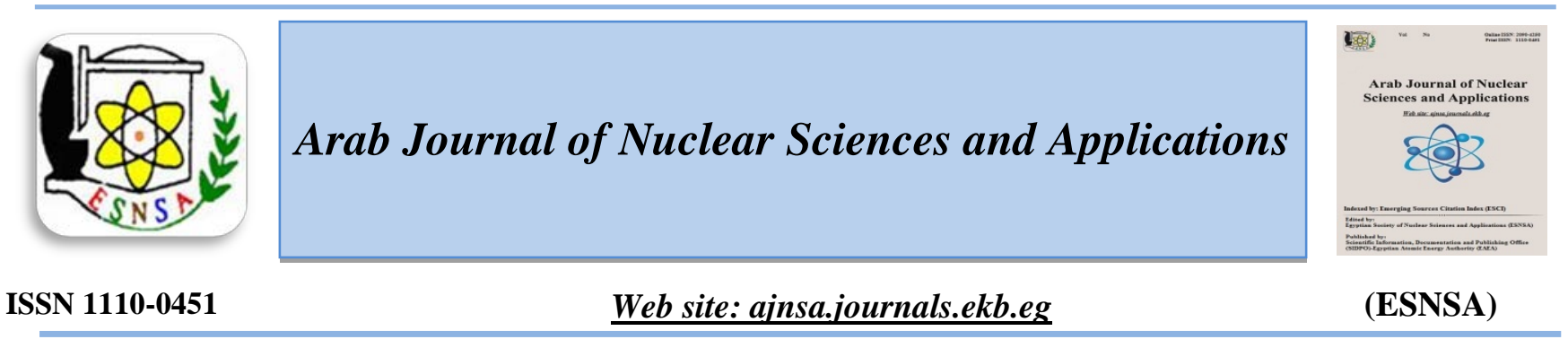

\title{
The Effect of Simple Vertical Fraction on Diffusion Equation with Deposition
}

\author{
Khaled S. M. Essa ${ }^{1}$, Ahmed M. Mosallem ${ }^{1}$, Ayman A. Khalifa ${ }^{2}$ and A. S. Shalaby ${ }^{2}$ \\ ${ }^{1}$ Department of Mathematics and Theoretical Physics, Nuclear Research Center, Atomic Energy Authority, \\ Cairo, Egypt, \\ ${ }^{2}$ Department of of Physics, Faculty of Science, Beni-Suef University, Egypt
}

\begin{abstract}
Received $22^{\text {th }}$ July 2019 The vertical fraction variation of eddy diffusivity was taken into consideration in the dispersion of Accepted $3^{\text {th }}$ March 2020 pollutants from a point source. A power-law profile was used to describe the variation of wind speed and vertical eddy diffusivity with height above ground surface. The dry deposition of the diffusing particles at the ground surface is taken into account through the boundary conditions. The concentration of pollutants was derived assuming that the vertical diffusion is limited by an elevated inversion layer located at the top of the boundary layer "h". Also, the decay distance of a pollutant along the wind direction was estimated. The resulting analytical solutions have been applied on the emissions from Egypt's First Research Reactor at Inshas in unstable condition and Hanford diffusion experiment in stable condition. Comparisons between proposed and observed concentrations show a good agreement between the proposed and observed concentrations when $\alpha=0.81$ than other fractions and integer value. The results are discussed and presented in illustrative figures.
\end{abstract}

Keywords: Power law of wind speed,vertical fraction,decay distance of a polutant,Inshasand Hanford experiments:

\section{Introduction}

The diffusion of pollutants in the atmosphere is an important source of problems due to their physical fields. The turbulence is the reason behind the dispersion of pollutants in the atmosphere.

Fractional differential equations had been used to describe many natural phenomena [1-4]. This estimation had only recently obtained practical applications. However, in this way, the fractional estimation became a very useful tool to study diffusion and other transportation processes, initially with more attention to the hydrological environment [5-6]. Some papers had contained a good description of the recent applications of fractional calculus to science and engineering [79].

Many authors had derived the exact solutions of the advection-diffusion equation with dry deposition on the ground surface and for power law profiles of the vertical eddy diffusivity and wind speed in the unbounded atmosphere (infinite mixing/inversion layer) for the ground level area and point sources, respectively[10-16].However, an assumption of infinite unbounded atmospheric boundary layer (ABL) in derivation of these solutions is not physically realistic because of the formation of finite inversion/mixing layer in lower

Corresponding author: mohamedksm56@yahoo.com

DOI: 10.21608/ajnsa.2020.15115.1241

(C) Scientific Information, Documentation and Publishing Office (SIDPO)-EAEA 
atmosphere that restrict the vertical pollutant diffusion.

Recently, the solutions of the two-dimensional advection-diffusion equation by considering the deposition on the ground surface were derived [1718]. However, the mathematical techniques were used to solve the advection-diffusion equation and also in other numerical or analytical solutions were required to verify with an exact solution of this equation. Analytical solutions of fractional differential equations applied to practical problems still require more attention. Moreover, this work proposed the extension of a well-known method with the inclusion of fractional derivatives in the advection-diffusion equation [19-20].

In this study, an analytical treatment of the diffusion equation is presented under the boundary conditions which include the deposition of pollutants on the ground surface. The power-law profile was used to describe the variation of wind speed and vertical eddy diffusivity with vertical height above ground surface. The vertical fraction is taken to be limited by an elevated inversion layer, which tends to reflect back the air pollutants hitting the inversion base. The resulting analytical formulae have been applied on a case study namely, the emissions from the Research Reactor at Inshas in unstable condition and Hanford diffusion experiment in stable condition. Statistical measurements were used to evaluate the performance of the derived solution. The values of these measures show a good agreement between the observed and predicted concentrations when " $\alpha=0.81$ " compared to others fractions and integer value. The results are discussed and presented in illustrative figures---.

\section{Mathematical Description}

The diffusion equation in the steady state which describes the dispersion of pollutants in a turbulent atmospheric boundary layer is given as follows[21]:

$$
u \frac{\partial C}{\partial x}+v \frac{\partial C}{\partial y}+\omega \frac{\partial C}{\partial z}=\frac{\partial}{\partial x}\left(k_{x} \frac{\partial C}{\partial x}\right)+\frac{\partial}{\partial y}\left(k_{y} \frac{\partial C}{\partial y}\right)+\frac{\partial}{\partial z}\left(k_{z} \frac{\partial C}{\partial z}\right)+R+S
$$

where $C=C(x, y, z)$ is the mean contaminant concentration $\left(\mathrm{g} / \mathrm{m}^{3}\right), u, v, \omega, k_{x}, k_{y}$ and $k_{z}$ are the components of wind velocity $(\mathrm{m} / \mathrm{s})$ and eddy diffusivity coefficient $\left(\mathrm{m}^{2} / \mathrm{s}\right)$ along the $x, y$, and $z$ directions, respectively, $S$ and $R$ are the source and removal terms.
The following assumptions are used to simplify Eq. (1):

1- The mean wind velocity is along the $x$-axis, i.e. $v=\omega=0$.

2- The diffusion in the direction of the mean wind is neglected compared to the advection in that direction.

3- The source and removal terms are ignored so that, $\mathrm{S}=0$ and $\mathrm{R}=0$.

Therefore Eq. (1) is reduced to:

$$
u \frac{\partial C}{\partial x}=\frac{\partial}{\partial y}\left(k_{y} \frac{\partial C}{\partial y}\right)+\frac{\partial}{\partial z}\left(k_{z} \frac{\partial C}{\partial z}\right)
$$

The solution of Eq. (2) can be obtained as follows: 1- Integrating Eq. (2) with respect to $y$ from $-\infty$ to $\infty$, leads to

$$
u \frac{\partial C_{y}}{\partial x}=\frac{\partial}{\partial z}\left(k_{z} \frac{\partial C_{y}}{\partial z}\right)
$$

Where $C_{y}$ is the crosswind integrated concentration is given by:

$$
C_{y}=\int_{-\infty}^{\infty} C(x, y, z) d y
$$

2- Assuming the concentration distribution of pollutants in the crosswind direction is Gaussian, therefore, the three dimensional solution of Eq.

(2) can be written as follows [22]:

$$
C(x, y, z)=\frac{1}{\sqrt{2 \pi} \sigma_{y}} C_{y}(x, z) \exp \left[-\frac{y^{2}}{2 \sigma_{y}^{2}}\right]
$$

where, $\sigma_{y}$ is the lateral dispersion parameter $(m)$.

A power-law profile is used to describe the variation of wind speed and vertical eddy diffusivity with height $z$ in the atmospheric boundary layer as:

$u(z)=\beta z^{p}, \beta=u_{r} z_{r}^{-p}(6)$

$k(z)=k_{0}+\gamma z^{n}, \gamma=k_{r} z_{r}^{-n}(7)$

where $p$ and $n$ are the power-law exponent of wind speed and eddy diffusivity respectively, $u_{r}$ and $k_{r}$ are the wind speed and the eddy diffusivity at the reference height $z_{r}$ respectively. The exponents $p$ and $n$ are functions of the atmospheric stability and nature of underlying surface.

Equation (3) is solved under the following boundary conditions:

$$
\begin{aligned}
& \boldsymbol{c}_{\boldsymbol{y}}(\boldsymbol{x}, \mathbf{z})=\mathbf{0} \text { at } z=\boldsymbol{h} \\
& k_{z} \frac{\partial C_{y}(x, z)}{\partial z}=0 \text { at } z=h
\end{aligned}
$$

Corresponding author: mohamedksm56@yahoo.com 


$$
\begin{gathered}
k_{z} \frac{\partial C_{y}(x, z)}{\partial z}=v_{d} C_{y}(x, z) \text { at } z=0 \\
Q=\int_{0}^{x_{d}} \int_{0}^{h} u(z) C_{y}(x, z) d z d x
\end{gathered}
$$

It is noticed that $k_{z}(z=0)=k_{0}$. Thediffusion coefficient should be non-zero at the ground surface for vertical diffusion to be possible. Where $Q$ is the emission rate, $h$ is the mixing height, $v_{d}$ is the deposition velocity of apollutant and $x_{d}$ is the decay distance of a pollutant radioactive or industrial.

Assuming the solution of Eq. (3) has the form [10]:

$C_{y}(x, z)=F(x)\left(1-\frac{z}{h}\right)^{\alpha}$

where, $0<\alpha \leq 1$. Integrating Eq. (3) with respect to " $z$ " from 0 to $h$ and applying the boundary conditions Eqs. (8a-8c), yields:

$$
\frac{d}{d x} \int_{0}^{h} u C_{y}(x, z) d z=-v_{d} C_{y}(x, 0)(10)
$$

We substitute from two Eqs. (6 and 9) in Eq. (10), on gets:

$$
\beta \frac{d F(x)}{d x} \int_{0}^{h} z^{p}\left(1-\frac{z}{h}\right)^{\alpha} d z=-v_{d} F(x)(11
$$

Let:

$$
N=\int_{0}^{h} z^{p}\left(1-\frac{z}{h}\right)^{\boldsymbol{\alpha}} d z
$$

Therefore, Eq.(11) takes the form:

$$
\frac{d F}{d x}=-\frac{v_{d}}{\beta N} F(x)
$$

and has the following solution:

$$
F(x)=F_{0} e^{-\frac{v_{d}}{\beta N} x}=F_{0} e^{-\frac{x}{x_{d}}}(14)
$$

Where $F_{0}$ is a constant of integration and

$$
x_{d}=\frac{\beta N}{v_{d}}
$$

is called the decay distance of air borne pollutant radioactive or industrial. The concentration formula Eq. (9) can be written as:

$$
C_{y}(x, z)=F_{0} e^{-\frac{x}{x_{d}}}\left(1-\frac{z}{h}\right)^{\alpha}
$$

To determine $F_{0}$, substitute by Eq. (16) in the boundary condition Eq.(8d)yields:

$$
\begin{gathered}
Q=\beta F_{0} \int_{0}^{x_{d}} e^{-\frac{x}{x_{d}}} \int_{0}^{h} z^{p}\left(1-\frac{z}{h}\right)^{\alpha} d z d x \\
=\beta F_{0} \int_{0}^{x_{d}} e^{-\frac{x}{x_{d}}} N d x \\
=x_{d}^{2} v_{d} F_{0}\left(1-\frac{1}{e}\right)
\end{gathered}
$$

Then,

$$
F_{0}=\frac{Q e}{x_{d}^{2} v_{d}(e-1)}
$$

Therefore, the crosswind integrated concentration takes the form:

$$
C_{y}(x, z)=\frac{Q e}{x_{d}^{2} v_{d}(e-1)} e^{-\frac{x}{x_{d}}}\left(1-\frac{z}{h}\right)^{\alpha}
$$

Eq. (5) is the general solution of Eq. (2) which can be written as:

$$
C(x, y, z)=\frac{Q e}{\sqrt{2 \pi} \sigma_{y} x_{d}^{2} v_{d}(e-1)} e^{-\left[\frac{y^{2}}{2 \sigma_{y}^{2}}+\frac{x}{x_{d}}\right]}\left(1-\frac{z}{h}\right)^{\alpha}
$$

\section{Results and Discussion}

In this work, an analytical solution of the three dimensional advection-diffusion equation is presented taking into account the dry deposition of the pollutants at ground surface. The derived concentration formula (Eq.20)was evaluated against the data of ${ }^{135}$ I (lodine-135) obtained from Inshas experiment.

\section{1- Inshas dispersion experiments in unstable conditions}

The data used to calculate the concentration of I-135 isotope was obtained from dispersion experiments conducted in unstable conditions to collect air samples around the Research Reactor at Inshas. The samples were collected at a height of $0.7 \mathrm{~m}$ above ground. The emissions were released from a stack of height $43 \mathrm{~m}$. The Reactor site was flat and dominated by sandy soil with a poor vegetation cover with a roughness length of $0.6 \mathrm{~cm}$. The deposition velocity of lodine $\underline{v}_{d}$ $=0.01 \mathrm{~m} / \mathrm{s}$. The measured concentration of $1-135$ isotope and the meteorological data during the experiments are taken as described in a previous study[23] and presented in Table (1).The values of power-law exponent $\mathrm{p}$ and $\mathrm{n}$ of wind speed and eddy diffusivity as a function of air stability are taken from ref. [24] and presented in Table(2). 
The crosswind dispersion parameter oy was calculated using Briggs formula [25]in urban area, (Table 3). The predicted concentrations by Eq. (20) below the plume center line are presented in Table (1). A comparison between predicted and observed concentrations of $1-135$ in unstable condition at Inshas are shown in Figs.(1 and 2).

\section{2- Hanford diffusion experiment in stable conditions}

The diffusion experiment was conducted at Hanford, south eastern Washington $\left(46^{\circ} 34^{\prime} \mathrm{N}, 119^{\circ} 36^{\prime} \mathrm{W}\right)$ USA during May-Jun, 1983 on flat terrain with a roughness length of $3 \mathrm{~cm}$. Two tracers, one depositing tracer zinc sulfide $(\mathrm{ZnS})$ and one gaseous sulfur hexafluoride $\left(\mathrm{SF}_{6}\right)$ were released at a height of $2 \mathrm{~m}$ above ground surface. Concentrations were measured at five sampling arcs 100, 200, 800, 1600 and $3200 \mathrm{~m}$ downwind from the source during moderately stable to nearneutral conditions. The samples were collected on each arc at a height of $1.5 \mathrm{~m}$ above ground surface. The deposition velocity $v_{d}$ was evaluated only for the last three distances. The collected data during the field tests were tabulated as crosswind integrated concentrations. Detailed description of the experiment was supplied in an earlier study [26]. The meteorological data and the crosswind integrated concentration data normalized by emission rate $Q$ during the field tests were taken froma previous publication [26] and presented in Table (4). The height of the mixing layer $h$, not presented in the Hanford dataset, was calculated by the following formula $[10,27]$ for stable air:

$$
h=0.4\left(u_{*} \frac{L}{|f|}\right)^{\frac{1}{2}}, \quad \text { for } \frac{h}{L}>0(21)
$$

where, $f=2 \Omega \sin \Phi$ is the Coriolis parameter, $\Omega$ is the angular velocity of the earth and $\Phi$ is the latitude. The values of the friction velocity $u_{*}$ and the Monin- Obukhove length $L$ for each run are presented in Table (4).

The predicted normalized crosswind integrated concentrations $(C(x, z) / Q)$ by Eq.(19) are presented in Table (4). A comparison between the predicted and observed normalized crosswind integrated concentrations of $\mathrm{ZnS}$ in stable condition (Hanford experiment) are shown in Figs.(3 and 4).

Statistical measures were used to evaluate the performance of the new model; their values are presented in Table (5). Figure (1) shows a good agreement between the observed concentrations of $135 \mathrm{I}$ and the corresponding values predicted at ' $\alpha=0.81$ ' by the derived formula Eq. (20) compared to other fractions and an integer value in unstable conditions. Also, Figure (2) illustrates that all values of the predicted concentrations by the new model Eq. (20) are inside a factor of two, so it presents a good agreement between the predicted and observed values The scatter diagram of the observed and predicted normalized crosswind integrated concentrations by the new model Eq. (19) reveals that all points lie within a factor of two, so it presents a good agreement between the predicted and observed values. Figure (3) shows a reasonable agreement in most points between the predicted and observed normalized crosswind integrated concentrations at ' $\alpha=0.81^{\prime}$ by the derived formula Eq. (19) compared to other fractions and an integer value in stable conditions.

\section{4- MODEL EVALUATION STATISTICS}

To evaluate the model accuracy the following statistical idiocies that characterize the agreement between the predicted and observed concentrations were used. These measures are discussed by Hanna [28] and defined as:

$$
\text { Fraction Bias }(\mathrm{FB})=\frac{\left(\overline{C_{o}}-\overline{C_{p}}\right)}{\left[0.5\left(\overline{C_{o}}+\overline{C_{p}}\right)\right]}
$$

Normalized Mean Square Error (NMSE) $=\frac{\overline{\left(C_{p}-C_{o}\right)^{2}}}{\overline{\left(C_{p} c_{o}\right)}}$

Correlation Coefficient $(\mathrm{COR})=\frac{1}{N_{m}} \sum_{i=1}^{N_{m}}\left(C_{p i}-\overline{C_{p}}\right) \times \frac{\left(C_{o i}-\overline{C_{o}}\right)}{\left(\sigma_{p} \sigma_{o}\right.}$

$$
\text { Factor of Two }(\text { FAC2 })=0.5 \leq \frac{\mathrm{C}_{\mathrm{p}}}{\mathrm{C}_{\mathrm{o}}} \leq 2.0
$$

where $\sigma_{p}$ and $\sigma_{o}$ are the standard deviations of predicted $\left(C_{p}=C_{p r e d}\right)$ and observed $\left(C_{0}=C_{\text {obs }}\right)$ concentration respectively. The overbar indicates the average value. The perfect model must have the following performances: $\mathrm{NMSE}=\mathrm{FB}=0$ and $\mathrm{COR}=$ $\mathrm{FAC2}=1.0$.

Corresponding author: mohamedksm56@yahoo.com

DOI: 10.21608/ajnsa.2020.15115.1241

(C) Scientific Information, Documentation and Publishing Office (SIDPO)-EAEA 
Table (1): Meteorological parameters and concentrations measured at Inshas in unstable b condition and the corresponding values predicted by Eq. (20)

\begin{tabular}{|c|c|c|c|c|c|c|c|c|c|c|c|c|}
\hline $\begin{array}{c}R u \\
n\end{array}$ & $\begin{array}{c}\text { Sta } \\
b . \\
\text { clas } \\
s\end{array}$ & $\begin{array}{c}h \\
(m)\end{array}$ & $\begin{array}{c}\text { Win } \\
d \\
\text { Dire } \\
c . \\
(\text { deg } \\
\text { ) }\end{array}$ & $\begin{array}{c}U_{10} \\
m \\
(m / \\
s)\end{array}$ & $\begin{array}{c}Q \\
(B q)\end{array}$ & $\begin{array}{c}\text { Dis } \\
\text { t. } \\
\text { (m) }\end{array}$ & $\begin{array}{c}\text { Obs. } \\
C \\
(B q / \\
\left.m^{3}\right)\end{array}$ & $\begin{array}{c}\text { Pred. } \\
C \\
\alpha \\
=0.81 \\
(B q / \\
\left.m^{3}\right) \\
\end{array}$ & $\begin{array}{c}\text { Pred. } \\
C \\
\alpha \\
=0.86 \\
(B q / \\
\left.m^{3}\right) \\
\end{array}$ & $\begin{array}{l}\text { Pred. } \\
C \\
\alpha \\
=0.91 \\
(B q / \\
\left.m^{3}\right)\end{array}$ & $\begin{array}{l}\text { Pred. } \\
\quad C \\
\alpha \\
=0.99 \\
\left(B q / m^{3}\right.\end{array}$ & $\begin{array}{c}\text { Pred. } \\
C \\
\alpha=1 \\
(B q / \\
\left.m^{3}\right)\end{array}$ \\
\hline 1 & $A$ & 601 & 301 & 4 & $\begin{array}{c}10285 \\
71\end{array}$ & $\begin{array}{c}10 \\
0\end{array}$ & 0.025 & 0.08 & 0.08 & 0.09 & 0.10 & 0.10 \\
\hline 2 & A & 801 & 279 & 4 & $\begin{array}{c}10500 \\
00\end{array}$ & 98 & 0.037 & 0.06 & 0.07 & 0.07 & 0.08 & 0.08 \\
\hline 3 & B & 973 & 190 & 6 & $\begin{array}{c}42857 . \\
14\end{array}$ & $\begin{array}{c}11 \\
5\end{array}$ & 0.091 & 0.10 & 0.10 & 0.11 & 0.12 & 0.12 \\
\hline 4 & C & 888 & 198 & 4 & $\begin{array}{c}47142 \\
8.6\end{array}$ & $\begin{array}{c}13 \\
5\end{array}$ & 0.197 & 0.22 & 0.24 & 0.25 & 0.28 & 0.28 \\
\hline 5 & A & 921 & 182 & 4 & $\begin{array}{c}49285 \\
7.1\end{array}$ & 99 & 0.272 & 0.38 & 0.41 & 0.43 & 0.47 & 0.48 \\
\hline 6 & D & 443 & 347 & 4 & $\begin{array}{c}51428 \\
5.7\end{array}$ & $\begin{array}{c}18 \\
4\end{array}$ & 0.188 & 0.24 & 0.26 & 0.27 & 0.30 & 0.30 \\
\hline 7 & C & $\begin{array}{c}127 \\
1\end{array}$ & 331 & 4 & $\begin{array}{c}10071 \\
43\end{array}$ & $\begin{array}{c}16 \\
5\end{array}$ & 0.447 & 0.37 & 0.40 & 0.42 & 0.46 & 0.47 \\
\hline 8 & C & $\begin{array}{c}184 \\
2\end{array}$ & 188 & 4 & $\begin{array}{c}10435 \\
71\end{array}$ & $\begin{array}{c}13 \\
4\end{array}$ & 0.123 & 0.06 & 0.06 & 0.07 & 0.07 & 0.07 \\
\hline 9 & A & $\begin{array}{c}164 \\
2 \\
\end{array}$ & 142 & 4 & $\begin{array}{c}10339 \\
29 \\
\end{array}$ & 96 & 0.032 & 0.03 & 0.03 & 0.03 & 0.03 & 0.03 \\
\hline
\end{tabular}

Table (2): Power-law exponent $\mathrm{p}$ and $\mathrm{n}$ of wind speed and eddy diffusivity as a function of air stability in urban area

\begin{tabular}{ccccccc}
\hline & $A$ & $B$ & $C$ & $D$ & $E$ & $F$ \\
\hline$p$ & 0.15 & 0.15 & 0.20 & 0.25 & 0.40 & 0.60 \\
$n$ & 0.85 & 0.85 & 0.80 & 0.75 & 0.60 & 0.40 \\
\hline
\end{tabular}

Table(3:)Briggs formulas(1973) for $\sigma_{y}(x)$ and $\sigma_{z}(x)$ in urban area

\begin{tabular}{ccc}
\hline Stability classes & $\sigma_{z}(\mathrm{~m})$ & $\sigma_{y}(\mathrm{~m})$ \\
\hline A & $0.24 x(1+0.001 x)^{\frac{1}{2}}$ & $0.32 x(1+0.0004 x)^{-\frac{1}{2}}$ \\
B & $0.24 x(1+0.001 x)^{\frac{1}{2}}$ & $0.32 x(1+0.0004 x)^{-\frac{1}{2}}$ \\
C & $0.20 x$ & $0.32 x(1+0.0004 x)^{-\frac{1}{2}}$
\end{tabular}



D
$0.14 x(1+0.0003 x)^{-\frac{1}{2}}$
$0.16 x(1+0.0004 x)^{-\frac{1}{2}}$
E
$0.08 x(1+0.00015 x)^{-\frac{1}{2}}$
$0.11 x(1+0.0004 x)^{-\frac{1}{2}}$
$\mathrm{F}$
$0.08 x(1+0.00015 x)^{-\frac{1}{2}}$
$0.11 x(1+0.0004 x)^{-\frac{1}{2}}$

Table (4): Meteorological parameters and the crosswind integrated concentrations data normalized by $Q$ at Hanford experiment in stable conditions and the corresponding values predicted by Eq. (19)

\begin{tabular}{|c|c|c|c|c|c|c|c|c|c|c|c|c|}
\hline Date & $\begin{array}{c}u_{*} \\
(\mathrm{~cm} / \\
\mathrm{s})\end{array}$ & $\begin{array}{c}h \\
(m \\
)\end{array}$ & $\begin{array}{c}u \\
(\mathrm{~m} / \\
\mathrm{s})\end{array}$ & $\begin{array}{c}L \\
(m \\
)\end{array}$ & $\begin{array}{c}\bar{v}_{d} \\
(\mathrm{~cm} / \\
\mathrm{s})\end{array}$ & 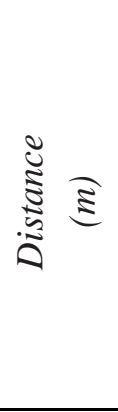 & $\begin{array}{c}\text { Obs. } \\
10^{-3} \\
C_{\mathrm{y}} / Q \\
{ }^{(} \\
\mathrm{sm}^{-2} \\
)^{-2}\end{array}$ & $\begin{array}{c}\text { Pred } \\
\cdot \\
10^{-} \\
{ }^{3} C_{\mathrm{y}} / \\
Q \\
Q \\
( \\
\mathrm{sm}^{-2} \\
) \\
\boldsymbol{\alpha} \\
=\mathbf{0 . 8 1}\end{array}$ & $\begin{array}{c}\text { Pred. } \\
10^{-} \\
{ }^{3} C_{\mathrm{y}} / Q( \\
\left.\mathrm{sm}^{-2}\right) \\
\boldsymbol{\alpha}=\mathbf{0 . 8 6}\end{array}$ & $\begin{array}{c}\text { Pred } \\
\cdot \\
10^{-} \\
{ }^{3} C_{\mathrm{y}} / \\
Q \\
( \\
\mathrm{sm}^{-2} \\
) \\
\boldsymbol{\alpha} \\
=0.91\end{array}$ & $\begin{array}{c}\text { Pred } \\
\cdot \\
10^{-} \\
{ }^{3} \mathrm{C}_{\mathrm{y}} / \\
Q \\
( \\
( \\
\mathrm{sm}^{-2} \\
) \\
\mathbf{\alpha} \\
=\mathbf{0} . \mathbf{9 9}\end{array}$ & 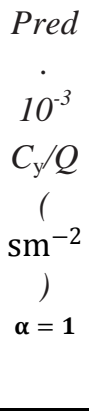 \\
\hline $\begin{array}{c}18 / 05 / \\
83\end{array}$ & 40 & $\begin{array}{c}32 \\
5\end{array}$ & $\begin{array}{c}7.6 \\
1\end{array}$ & $\begin{array}{c}16 \\
6\end{array}$ & 4.21 & & 2.24 & 2.29 & 2.29 & 2.28 & 2.26 & 2,26 \\
\hline $\begin{array}{c}26 / 05 / \\
83\end{array}$ & 26 & $\begin{array}{c}13 \\
5\end{array}$ & $\begin{array}{c}3.2 \\
3\end{array}$ & 44 & 1.93 & & 7.47 & 7.89 & 7.58 & 7.27 & 6.75 & 6,69 \\
\hline $\begin{array}{c}05 / 06 / \\
83\end{array}$ & 27 & $\begin{array}{c}18 \\
2\end{array}$ & $\begin{array}{c}4.7 \\
4\end{array}$ & 77 & 3.14 & & 3.06 & 4.39 & 4.19 & 3.98 & 3.65 & 3,61 \\
\hline $\begin{array}{c}12 / 06 / \\
83\end{array}$ & 20 & $\begin{array}{c}10 \\
4\end{array}$ & $\begin{array}{c}3.0 \\
0\end{array}$ & 34 & 1.75 & 800 & 8.04 & 7.15 & 6.64 & 6.15 & 5.41 & 5,32 \\
\hline $\begin{array}{c}24 / 06 / \\
83\end{array}$ & 26 & $\begin{array}{c}15 \\
7\end{array}$ & $\begin{array}{c}3.0 \\
7\end{array}$ & 59 & 1.56 & & 5.25 & 5.69 & 5.68 & 5.65 & 5.59 & 5,58 \\
\hline $\begin{array}{c}27 / 06 / \\
83 \\
\end{array}$ & 30 & $\begin{array}{c}18 \\
5 \\
\end{array}$ & $\begin{array}{c}3.1 \\
7 \\
\end{array}$ & 71 & 1.17 & & 7.23 & 6.52 & 6.7 & 6.87 & 7.12 & 7,15 \\
\hline $\begin{array}{c}18 / 05 / \\
83\end{array}$ & 40 & $\begin{array}{c}32 \\
5\end{array}$ & $\begin{array}{c}8.5 \\
3\end{array}$ & $\begin{array}{c}16 \\
6\end{array}$ & $\begin{array}{c}4.0 \\
5\end{array}$ & & $\begin{array}{c}0.98 \\
2\end{array}$ & $\begin{array}{c}0.86 \\
2\end{array}$ & 0.808 & $\begin{array}{c}0.75 \\
4\end{array}$ & $\begin{array}{c}0.67 \\
4\end{array}$ & $\begin{array}{c}0.66 \\
4\end{array}$ \\
\hline $\begin{array}{c}26 / 05 / \\
83\end{array}$ & 26 & $\begin{array}{c}13 \\
5\end{array}$ & $\begin{array}{c}3.5 \\
9\end{array}$ & 44 & $\begin{array}{c}1.8 \\
0\end{array}$ & & 3.25 & 2.97 & 2.59 & 2.26 & 1.79 & 1,74 \\
\hline $\begin{array}{c}05 / 06 / \\
83\end{array}$ & 27 & $\begin{array}{c}18 \\
2\end{array}$ & $\begin{array}{c}5.4 \\
0\end{array}$ & 77 & $\begin{array}{c}3.0 \\
2\end{array}$ & & 1.32 & 1.09 & 0.94 & 0.8 & 0.61 & 0.59 \\
\hline $\begin{array}{c}12 / 06 / \\
83\end{array}$ & 20 & $\begin{array}{c}10 \\
4\end{array}$ & $\begin{array}{c}3.3 \\
9\end{array}$ & 34 & $\begin{array}{c}1.6 \\
2\end{array}$ & 0 & 4.26 & 4.08 & 3.36 & 2.76 & 2.00 & 1,92 \\
\hline $\begin{array}{c}24 / 06 / \\
83\end{array}$ & 26 & $\begin{array}{c}15 \\
7\end{array}$ & $\begin{array}{c}3.2 \\
4\end{array}$ & 59 & $\begin{array}{c}1.4 \\
7\end{array}$ & & 3.38 & 3.18 & 2.98 & 2.78 & 2.47 & 2,44 \\
\hline $\begin{array}{c}27 / 06 / \\
83\end{array}$ & 30 & $\begin{array}{c}18 \\
5 \\
\end{array}$ & $\begin{array}{c}3.8 \\
0 \\
\end{array}$ & 71 & $\begin{array}{c}1.1 \\
5 \\
\end{array}$ & & 2.52 & 2.75 & 2.71 & 2.67 & 2.58 & 2,57 \\
\hline $\begin{array}{c}18 / 05 / \\
83\end{array}$ & 40 & $\begin{array}{c}32 \\
5\end{array}$ & $\begin{array}{c}9.4 \\
3\end{array}$ & $\begin{array}{c}16 \\
6\end{array}$ & $\begin{array}{c}3.6 \\
5\end{array}$ & 3200 & $\begin{array}{c}0.58 \\
6\end{array}$ & $\begin{array}{c}0.54 \\
4\end{array}$ & 0.480 & $\begin{array}{c}0.38 \\
4\end{array}$ & $\begin{array}{c}0.28 \\
8\end{array}$ & $\begin{array}{c}0.28 \\
8\end{array}$ \\
\hline $26 / 05 /$ & 26 & 13 & 3.8 & 44 & 1.7 & & 2.31 & 1.60 & 1.60 & 1.60 & 1.60 & 1,60 \\
\hline
\end{tabular}

Corresponding author: mohamedksm56@yahoo.com

DOI: 10.21608/ajnsa.2020.15115.1241

(C) Scientific Information, Documentation and Publishing Office (SIDPO)-EAEA 


\begin{tabular}{|c|c|c|c|c|c|c|c|c|c|c|c|}
\hline 83 & & 5 & 3 & & 4 & & & & & & \\
\hline $\begin{array}{c}05 / 06 / \\
83\end{array}$ & 27 & $\begin{array}{c}18 \\
2\end{array}$ & $\begin{array}{c}6.3 \\
2\end{array}$ & 77 & $\begin{array}{c}2.8 \\
4\end{array}$ & $\begin{array}{c}0.66 \\
2\end{array}$ & $\begin{array}{c}0.79 \\
4\end{array}$ & 0.794 & $\begin{array}{c}0.79 \\
4\end{array}$ & $\begin{array}{c}0.79 \\
4\end{array}$ & $\begin{array}{c}0.79 \\
4\end{array}$ \\
\hline $\begin{array}{c}12 / 06 / \\
83\end{array}$ & 20 & $\begin{array}{c}10 \\
4\end{array}$ & $\begin{array}{c}3.7 \\
5\end{array}$ & 34 & $\begin{array}{c}1.3 \\
1\end{array}$ & 3.14 & 1.60 & 1.60 & 1.60 & 1.60 & 1,60 \\
\hline $\begin{array}{c}24 / 06 / \\
83\end{array}$ & 26 & $\begin{array}{c}15 \\
7\end{array}$ & $\begin{array}{c}3.4 \\
6\end{array}$ & 59 & $\begin{array}{c}1.1 \\
4\end{array}$ & 2.92 & 2.97 & 2.58 & 2.22 & 1.74 & 1.71 \\
\hline $\begin{array}{c}27 / 06 / \\
83\end{array}$ & 30 & $\begin{array}{c}18 \\
5\end{array}$ & $\begin{array}{c}4.3 \\
7\end{array}$ & 71 & $\begin{array}{c}1.1 \\
0\end{array}$ & 1.25 & 1.24 & 1.13 & 1.03 & $\begin{array}{c}0.87 \\
6\end{array}$ & $\begin{array}{c}0.85 \\
8\end{array}$ \\
\hline
\end{tabular}

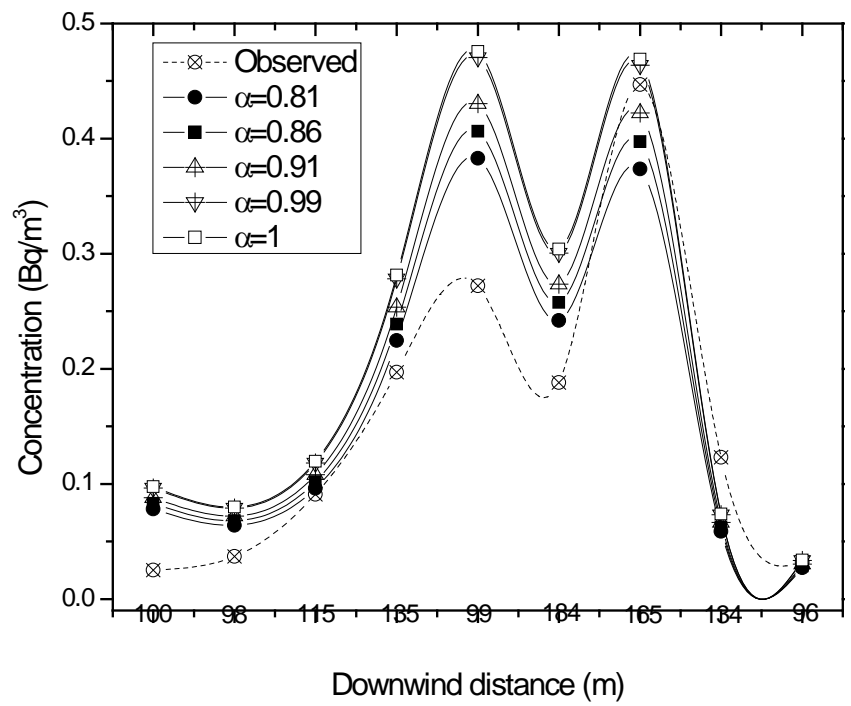

Fig. (1): Predicted and observed concentrations of ${ }^{135} \mathrm{I}$ via downwind distance in unstable condition at Inshas

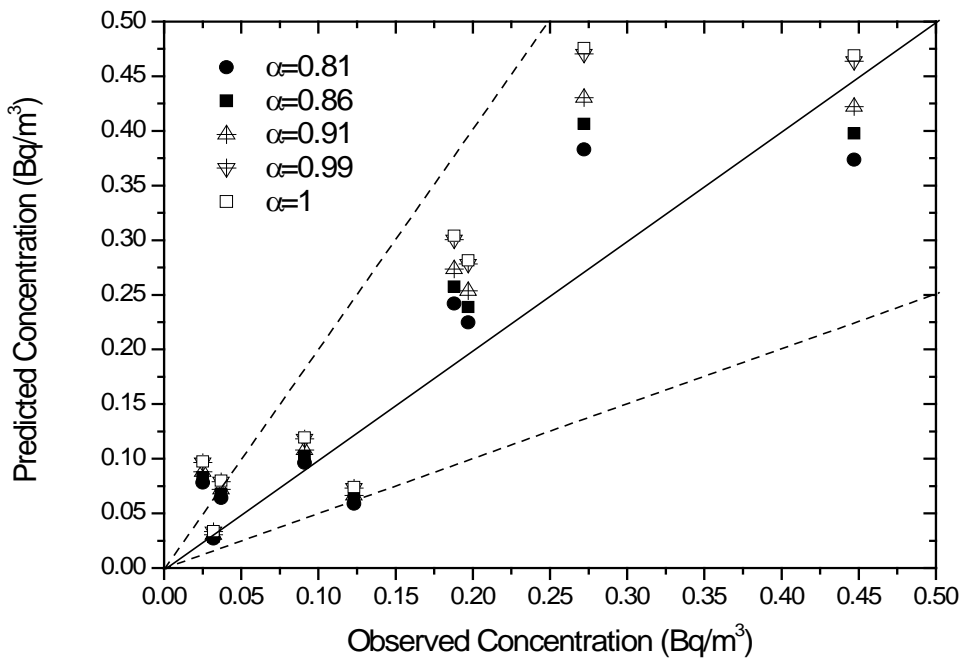

Fig. (2): Scatter diagram of observed and predicted concentrations of I-135 by the new model in unstable condition at Inshas. The solid line and dashed lines indicate a one to one line and a factor of two respectively 

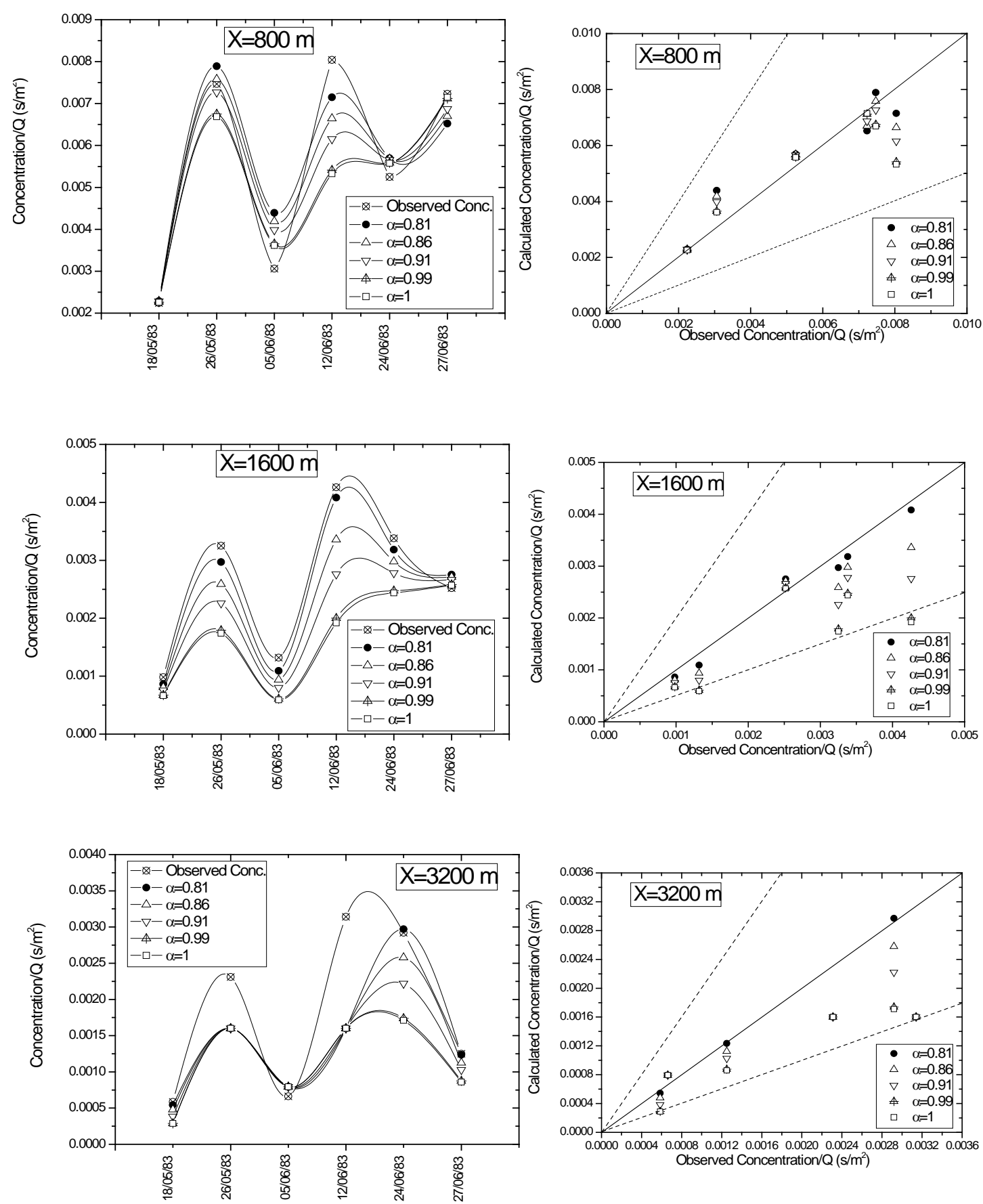

a

Fig. (3): Calculated normalized crosswind integrated concentrationsof ZnS againest the corrsponding observed values at Hanford experiment in stable condition. Dashed lines indicate a factor of two, solid line is the one-to-one line.

Corresponding author: mohamedksm56@yahoo.com

DOI: 10.21608/ajnsa.2020.15115.1241

(C) Scientific Information, Documentation and Publishing Office (SIDPO)-EAEA 


\begin{tabular}{|c|c|c|c|c|c|}
\hline Experumentsa & $\infty=$ & WMEE & FBa & COKa & FACEI \\
\hline \multirow{5}{*}{$\begin{array}{l}\text { - Hanfordat distancet } \\
\text { 800ms }\end{array}$} & 0.81 II & $0.02 \pi$ & -0.020 & 0.950 & 1.020 \\
\hline & 0.860 & 0.020 & $-0.006=$ & $0.95=$ & 0.950 \\
\hline & 0.910 & 0.030 & $-0.03=$ & $0.93=$ & $0.97=$ \\
\hline & 0.990 & 0.050 & $-0.08=$ & $0.59=$ & $0.93=$ \\
\hline & 1.000 & 0.05 & $-0.08=$ & $0.83=$ & $0.92=$ \\
\hline \multirow{4}{*}{$\begin{array}{c}\text { - Hentord-at-disancef } \\
1600 m \text { I }\end{array}$} & $0.81=$ & 0.0070 & 0.06 & $0.99=$ & 0.955 \\
\hline & $0.86=$ & $0.05=$ & 0.160 & $0.96=$ & 0.850 \\
\hline & $0.91=$ & $0.13=$ & 0.270 & 0.900 & $0.77=$ \\
\hline & $0.99=$ & $0.39=$ & 0.430 & 0.760 & $0.64=$ \\
\hline \multirow{6}{*}{$\begin{array}{c}\text { - Hanfoudat-disance } \\
\text { 3200me }\end{array}$} & $1.00=$ & $0.30=$ & 0.456 & $0.74=$ & $0.63=$ \\
\hline & $0.81 \pm$ & $0.1 \mathrm{~s}$ & $0.21=$ & $0.32=$ & $0.81 a$ \\
\hline & 0,960 & $0.21=$ & 0.280 & $0.57=$ & 0.750 \\
\hline & $0.91=$ & 0.250 & $0.35=$ & $0.92=$ & 0.70n: \\
\hline & $0.95 \%$ & $0.36=$ & 0.450 & 0.940 & 0.640 \\
\hline & 1.000 & 0.360 & 0.450 & $0.49=$ & 0.640 \\
\hline \multirow{5}{*}{ - Inshason } & 0.810 & $0.12=$ & $-0.09=$ & $0.91=$ & 1.100 \\
\hline & 0.860 & $0.14=$ & -0.150 & 0.916 & 1.160 \\
\hline & $0.91=$ & $0.16=$ & $-0.21 \mathrm{a}$ & $0.91 \mathrm{a}$ & 1.240 \\
\hline & 0.998 & 0.230 & -0.300 & $0.91 \mathrm{a}$ & 1.350 \\
\hline & $1.00=$ & $0.24=$ & $-0.32=$ & 0.910 & 1.379 \\
\hline
\end{tabular}

Table (5): Statistical evaluation of the present model against the Hanford and Inshas experiments

The values of the statistical indices (Table 5) reveal a reasonable agreement between predicted and observed concentrations at Hanford experiment in stable conditions, and Inshas experiment during unstable air.

\section{CONCLUSIONS}

The concentration of pollutants isobtained under unstable and stable condition assuming that the vertical fraction is limited by an elevated mixing layer. The decay distance of a pollutant along the wind direction is derived. The resulting analytical formulae have been applied on Inshas experiment under unstable conditions and Hanford experiment in stable conditions. A good agreement between the predicted and observed concentrations when $\boldsymbol{\alpha}=\mathbf{0 . 8 1}$ was found compared to other fractions and an integer value. Also, the values of the statistical measurements reveal a good agreement between predicted and observed concentrations at Inshas and Hanford experiments when $\alpha=0.81$ in comparison to other fractions and an integer value.

\section{References}

1- Zaslavsky, G., 1994: Fractional kinetic equation for Hamiltonian chaos, chaotic advection, tracer dynamics and turbulent o.

dispersion. Physica D, 76, 110-122, https://doi.org/10.1016/01672789(94)90254-2.

2- ] Meerschaert, M. M., and C. Tadjeran, 2004: Finite difference approximations for fractional advection-dispersion flow equations. J. Comput. Appl. Math., 172, 65-77, https://doi.org/10.1016/j.cam.2004.01.03 3.

3- Gorenflo, R., and F. Mainardi, 2009: Some recent advances in theory and simulation of fractional diffusion processes. J. Comput. Appl. Math., 229, 400-415, https://doi.org/10.1016/ j.cam.2008.04.005.

4- Schumer, R., M. M. Meerschaert, and B. Baeumer, 2009: Fractional advectiondispersion equations for modeling transport at the Earth surface. J. Geophys.

Arab J. Nucl. Sci. \& Applic. Vol. 53, No. 2 (2020) 
Res., 114, F00A07, https://doi.org/ 10.1029/2008JF001246.

5- Benson, D. A., M. M. Meerschaert, and J. Revielle, 2013: Fractional calculus in hydrologic modeling: A numerical perspective. Adv. Water Resour., 51, 479497,

https://doi.org/10.1016/j.advwatres.2012 .04 .005 .

6- Deseri, L., andM.Zingales, 2015:Amechanical picture of fractional order Darcy equation. Commun. Nonlinear Sci. Numer. Simul., 20, 940949, $\quad$ https://doi.org/10.1016/i. cnsns.2014.06.021.

7- Debnath, L., 2003: Recent applications of fractional calculus to science and engineering. Int. J. Math. Math. Sci., 2003, 3413-3442, https://doi.org/10. 1155/S0161171203301486.

8- Miller, K. S., and B. Ross, 1993: An Introduction to the Fractional Calculus and Fractional Differential Equations. 1st ed. Wiley- Interscience, $384 \mathrm{pp}$.

9- ] Podlubny, I., 1998: Fractional Differential Equations. Vol. 198, Mathematics in Science and Engineering, Academic Press, $340 \mathrm{pp}$.

10-Khaled S. M. Essa, Soad M.Etman., M. Embaby. (2007) New analytical solution of the dispersion equation. Atmos Res 87:337-344.

11- Vilhena, M.T., Costa, C.P., Moreira, D.M. and Tirabassi, T. (2008). A semi-analytical solution for the three-dimensional advection-diffusion equation considering non-local turbulence closure. Atmos. Res.90: 63-69.

12- Moreira, D.M., Vilhena, M.T., Buske D. and Tirabassi, T. (2009). The state-of-art of the GILTT method to simulate pollutant dispersion in the atmosphere. Atmos. Res.92: 1-17.

13- Kumar P, Sharan M (2010) An analytical model for dispersion of pollutants from a continuous source in the atmospheric boundary layer. Proc R Soc A 466:383406.

14- Kumar, P. and Sharan, M. (2012). Parameterization of the eddy diffusivity in a dispersion model over homogeneous terrain in the atmospheric boundary layer. Atmos. Res. 106: 30-43.

15- Chrysikopoulos, C.V., Hildemann, L.M. and Roberts, P.V. (1992). A three dimensional steady state atmospheric dispersion-deposition model for emissions from a ground-level area source. Atmos. Environ. 26: 747-757.

16- Lin, J.S., Hildemann, L.M., (1997). A generalized mathematical scheme to analytically solve the atmospheric diffusion equation with dry deposition. Atmos. Environ. 31, 59-71.

17- Tirabassi, T., Buske, D., Moreira, D.M. and Vilhena, M.T. (2008). A two dimensional solution of the advection-diffusion equation with dry deposition to the ground. J. Appl. Meteorol. Climatol.47: 2096-2014.

18- Kumar, P. and Sharan, M. (2014). A generalized analytical model for crosswind-integrated concentrations with ground-level deposition in the atmospheric boundary layer. Environ. Model. Assess. 19: 487-501.

19- Buske, D., 2004: Analytical solution of the advection-diffusion equation by the GILTT method applied to atmospheric pollutant dispersion. Dissertation, Postgraduate in Engineering Mechanics Program, Federal University of Rio Grande do Sul, 63 pp.

20- Moreira, D. M., T. Tirabassi, and T. T. Albuquerque, 2015: On the analytical formulations for pollutant dispersion simulation in the atmospheric boundary layer. Current Air Quality Issues, F. Nejadkoorki, Ed., InTech, 329-347.

21- Blackadar, A.K., 1997, Turbulence and diffusion in the atmosphere: lectures in Environmental Sciences, Springer-Verlag, 185p.

Corresponding author: mohamedksm56@yahoo.com

DOI: 10.21608/ajnsa.2020.15115.1241

(C) Scientific Information, Documentation and Publishing Office (SIDPO)-EAEA 
22-Khaled S. M. Essa, Soad M. Etman and Maha S. El-Otaify (2016). Studying the effect of vertical variation of wind speed and eddy diffusivity on the advectiondiffusion equation. Applied Science Reports, 14 (3), 250-257.

23- Khaled S.M. Essa, A.A. Marrouf, Maha S. El-Otaify, Adel S. Mohamed, Galal Ismail (2015), a new technique for solving the advection-diffusion equation in three dimensions using Laplace and Fourier transforms. J. Appl. Computa. Math. 4(5), 1-4.

24- Hanna, S.R., G.A. Briggs, Rayford, P. Hosker, JR.(1982): Handbook on Atmospheric Diffusion. DOE TIC- 11223 (DE 82002045).

25- Briggs, G.A. (1973): Diffusion estimation for small emissions. ATDL Contrib. 79 (draft), Air Resource Atmospheric Turbulence and Diffusion Laboratory, Oak, Ridge.

26- Doran J. C., and Horst T. W. (1985). "An evaluation of Gaussian plume-depletion models with dual-tracer fieldmeasurement". Atmos. Environ., 19, 939-951.

27- Arya, S.P., (1999). Air pollution Meteorology and Dispersion. Oxford University Press, New York, Oxford, P. 98.

28- Hanna, S.R. (1989): "Confidence Limit for Air Quality Models as Estimated by Bootstrap and Jacknife Resembling Methods", Atom. Environ. 23:1385-1395 